\title{
Sikap Inggris terhadap Indonesia menjelang pertempuran Surabaya 1945
}

\section{British attitude towards Indonesia prior to the Battle of Surabaya 1945}

\author{
I. Basis Susilo \\ Program Studi Hubungan Internasional, Fakultas Ilmu Sosial dan Ilmu Politik, \\ Universitas Airlangga \\ Jalan Dharmawangsa Dalam Selatan, Surabaya \\ E-mail: ib_susilo@yahoo.com
}

\begin{abstract}
This article discusses the difference of British Government decision maker's behavior towards Indonesia since Indonesian independence until the battle of Surabaya, 10 November 1945. There are two assumptions underlying this paper: (1) that behavioural differences are frequently happened and create crises and problems, and (2) that the differences rise were based on interests and each party's capacity that measured by the law of $A=f-I \& C$ (Attitude is the function of Interest \& Capability). Based on that assumptions, this article proposes two hypotheses: (1) that the Battle of Surabaya was initialized with differences of attitudes taken by the British decision makers. and (2) that the differences were shaped by the realities they were dealing with. This paper focuses on attitudes toward: (1) the task of the British force in the Netherlands East Indies, and (2) the need to confer with the Indonesian leaders. The findings are; not only decision maker's behaviour were different, they also dynamic depending on how they defined circumstances and development of events in Indonesia, in Netherlands, and international affairs.
\end{abstract}

Keywords: Attitudes, policy, British, Dutch, Indonesia, Battle of Surabaya of 10 November 1945

\begin{abstract}
Abstrak
Makalah ini membahas perbedaan sikap para pengambil keputusan yang mewakili pemerintah Inggris terhadap problem Indonesia sejak merdeka sampai terjadinya Pertempuran Surabaya 10 November 1945. Dua asumsi mendasari makalah ini: (1) bahwa perbedaan sikap sering terjadi dan menimbulkan krisis dan permasalahan, dan (2) bahwa perbedaan sikap disebabkan oleh kepentingan dan kapasitas masing-masing pihak yang bersikap itu sesuai rumus $\mathrm{S}=\mathrm{f}-\mathrm{K}(1+2)$. Atas dasar asumsi-asumsi itu diajukan dua hipotesis: (1) bahwa Pertempuran Surabaya 10 November 1945 diawali dengan pelbagai perbedaan sikap antar pejabat Inggris, dan (2) bahwa perbedaan itu dipengaruhi oleh konteks kepentingan dan kapasitas masing-masing pejabat dalam melihat realitas yang dihadapi. Sikap difokuskan pada terhadap dua ikhwal: (1) tugas pasukan Inggris di Hindia Belanda, dan (2) perlunya Belanda berunding dengan para pemimpin Indonesia. Temuan dari penelitian ini adalah bahwa perbedaan sikap tidak terletak hanya antar pejabat, tetapi juga dinamis tergantung pada definisi situasi atas dinamika perkembangan di Indonesia, di Belanda dan di lingkungan internasional.
\end{abstract}

Kata kunci: Sikap, kebijakan, Inggris, Belanda, Indonesia, Pertempuran Surabaya 1945

\section{Pendahuluan}

Makalah ini membahas perbedaan sikap dan kebijakan dari para pejabat Inggris yang berwenang dalam mengatasi persoalan Indonesia sejak kemerdekaan sampai terjadinya Pertempuran Surabaya pada 10 November 1945. Makalah ini adalah pengembangan dari artikel opini I.Basis Susilo, "Who Actually Killed Mallaby?” yang dimuat di The Jakarta Post, 10 November 2016, yang kemudian juga dengan judul yang sama dimuat di harian India, The Asian Age, pada 16 November 2016. Artikel itu mengekspos bahwa kejadian-kejadian (termasuk terbunuhnya Brigjen Mallaby) yang menyebabkan Pertempuran Surabaya pada 10 November 1945 disebabkan oleh tidak solidnya sikap para pejabat Inggris dalam menghadapi Persoalan Indonesia.

Untuk membahas perbedaan-perbedaan sikap para pejabat Inggris mengenai persoalan Indonesia, artikel ini merumuskan dua masalah: (1) Apa saja perbedaan sikap para pejabat Inggris terhadap persoalan Indonesia pada awal kemerdekaan sampai Pertempuran Surabaya 1945?; (2) Konteks, atau kepentingan dan kapasitas, apa yang menyebabkan adanya perbedaan-perbedaan sikap itu? 
Studi dalam hubungan internasional sering menyederhanakan masalah dengan menyatakan bahwa satu negara-bangsa punya satu sikap dasar, karena aktor utama adalah negara-bangsa. Atas dasar satu sikap dasar itu dibuatlah satu strategi nasional yang mesti diimplementasikan oleh pembuat-pembuat kebijakan di bawahnya. Dalam studi strategi, dikenal strategi besar (grand strategy), strategi (strategy), dan rencana-rencana operasional (operational plans). Strategi besar dibuat oleh aktor top level, strategi oleh middle level, dan operational plans oleh low level (Vrenken 2014:22). Kondisi idealnya, aktor middle level mengikuti dan tunduk pada aktor top level, aktor low level mengikuti dan tunduk pada aktor middle level. Bila kondisi ideal itu yang terjadi, sikap dan kebijakan Inggris mestinya coherent dan monolithic.

Tetapi, realitas tidak semudah itu. Tidak jarang, bahkan seringkali, masing-masing aktor mempunyai sikap yang berbeda, bahkan bertentangan dengan sikap aktor atasannya. Hal itu terjadi karena masingmasing aktor mempunyai tantangan dan informasinya sendiri yang bisa jadi berbeda aktor lain dalam satu negara-bangsa. Mengenai kemungkinan beda sikap itu dua pemelajar pernah menulis. Pertama, McMillan (2005:9) menulis: "Overall picture that emerges is one of confusion rather than the execution of a clear-cut plan". Pendapat McMillan didasari analisisnya bahwa kebijakan-kebijakan kolonial sering kontradiksi karena lebih didasari atas kedaruratan daripada atas agenda politik dan ideologik yang baku. Kedua, Nishijima mengenai sikap Jepang menulis (Sularto\&Yunarti 2010:146): "Suatu kesulitan lain bagi orang-orang Jepang ialah bagaimana melaksanakan kemerdekaan itu di tiga daerah terpisah, oleh karena pendapat penguasa di daerah-daerah tersebut ternyata tidak sama." Justru karenanya, kebijakan suatu negara-bangsa menjadi dinamik, dan hubungan antarnegara menjadi lebih kompleks dan menarik.

Perbedaan sikap itu lumrah terjadi karena pada dasarnya sikap adalah fungsi kepentingan dan kapasitas. Rumusnya adalah $\mathrm{S}=\mathrm{f}-\mathrm{K}(1+2)$, di mana $\mathrm{S}=\mathrm{Sikap}$, f=fungsi, $\mathrm{K}-1=$ Kepentingan, dan $\mathrm{K}$ $2=$ Kapasitas. Masing-masing melihat kepentingan dan kapasitasnya secara berbeda, karena mereka menghadapi tantangan riil di tempatnya masing-masing karena, seperti dinyatakan McMillan (Yahaya 2006:221) bahwa mereka bersikap atas dasar kemungkinan-kemungkinan (contigencies) yang tersedia di lapangan.

Atas dasar pemikiran itu, diajukan dua hipotesis: (1) bahwa Pertempuran Surabaya 10 November 1945 diawali dengan pelbagai perbedaan sikap baik antar pejabat Inggris, dan (2) bahwa perbedaanperbedaan itu disebabkan oleh definisi situasi yang dipengaruhi kepentingan dan kapasitas masingmasing pembuat keputusan.

\section{Metode Penelitian}

Untuk melihat sikap para pejabat Inggris, penelitian difokuskan terhadap dua sikap: (1) terhadap tugas utama Inggris di Indonesia, dan (2) terhadap perlu tidaknya perundingan Belanda dengan para pemimpin Indonesia. Sikap terhadap dua hal itu dicari dari data-data yang menunjukkan adanya sikap-sikap itu. Data-data dipilih dengan mengaitkannya dengan masing-masing aktor yang diteliti. Data-data tentang sikap para pejabat Inggris dipilah dan disusun atas dasar strata umum dari manajemen, yaitu: top level, middle level, dan low level.

Para pejabat Inggris yang diteliti adalah: Winston Churchill dan Clement R. Attlee (Perdana Menteri), Laksamana Sir Henry Maitland Wilson (British Joint Chief of Staff), Wakil Laksamana Lord Louis Mountbatten (Komandan Sekutu untuk Wilayah Asia Tenggara), Jendral Christison (Komandan Tentara Sekutu Hindia Belanda), Mayjen Douglas Hawthorn (Komandan Divisi India ke-23), Brigjen AWS Mallaby (Komandan Brigade ke-49 Divisi India Inggris), dan Mayjen E. C. Mansergh (Komandan Tentara Darat Sekutu di Jawa Timur, pengganti Mallaby).

Sikap seseorang bisa dilihat dari kata-katanya, dari tindakannya, dan dari tulisannya. Diskusi dan pembahasan terhadap sikap-sikap itu mempertimbangkan kepentingan dan kapasitasnya. Tentu saja, pembahasan tentang kepentingan dan kapasitas itu bersifat persepsional dan analitis, yang dicari dari 
analisis-analisis yang ada dalam literatur yang di-review. Teks dan konteks menjadi penting untuk dikemukakan dalam diskusi dan pembahasan atas temuan-temuan.

Metode yang dipakai adalah review literatur dari sumber primer dan sekunder. Data primer diambil dari korespondensi diplomatik dan berita-berita media massa pada waktu itu. Dalam hal korespondensi diplomatik, selain dari dua negara yang diteliti, juga diambil dari Amerika Serikat, yang secara teratur dan rinci melaporkan sikap-sikap terhadap problem Indonesia pada masa menjelang Pertempuran Surabaya. Sedangkan data sekunder diambil dari buku-buku yang membahas dan menganalisis atas dasar sumber-sumber primer itu. Dua sumber data sekunder utama yang dipakai adalah buku R. McMillan (2005) \& makalah Maikel Vrenken (2014).

Ruang lingkup penelitian ini adalah mulai 28 September sampai dengan 10 November 1945. Diambil 28 September sebagai batas awal adalah ketika untuk pertama kalinya Inggris mengirim pasukannya ke Jakarta, sedangkan 10 November diambil sebagai batas akhir adalah ketika Pertempuran Surabaya dimulai. Untuk memperjelas sikap pejabat Inggris yang diteliti, maka dibandingkan dengan sikap pejabat negara-negara lain yang dalam hal ini pejabat Belanda dan Amerika.

\section{Hasil dan Pembahasan}

Temuan dan diskusi terhadap temuan dibagi menjadi dua. Pertama, temuan berupa sikap-sikap terhadap tugas utama Inggris di Indonesia setelah Jepang menyerah pada Sekutu. Temuan-temuan dibahas dengan mempertimbangkan konteksnya dalam kepentingan dan kapasitas masing-masing. Kedua, temuan berupa sikap-sikap terhadap perlunya Belanda berunding dengan para pemimpin Indonesia. Hasil temuan juga dibahas dengan mempertimbangkan konteks dalam kepentingan dan kapasitas masing-masing.

\section{Sikap terhadap tugas Inggris di Indonesia}

Dalam perang Sekutu-Aliansi, wilayah Hindia Belanda -kecuali Sumatera- berada dalam "wilayah" tanggung jawab Amerika. Pada April 1945, Amerika meminta Inggris untuk mengambil tanggung jawab itu. Selanjutnya dalam Konferensi Postdam 24 Juli 1945 di mana dua perdana menteri Inggris hadir, Churchill dan Attlee, permintaan diulangi oleh Amerika dan disetujui Inggris (McMillan 2005:2-4). Oleh karena itu, sejak Jepang menyerah kepada Sekutu pada 14 Agustus 1945, tanggung jawab atas Hindia Belanda otomatis berada di bawah Pasukan Sekutu Asia Tenggara di bawah pimpinan Mountbatten (McMillan 2005:10).

Transfer itu didasari oleh strategi besar Amerika yang lebih berfokus pada tugas melakukan pukulan terakhir kepada Jepang, sehingga Hindia Belanda dianggap beban yang harus dilepas (Roem 1989:47, Kahin \& Kahin 1977:29-30). Sementara dari pihak Inggris, sikap Churchill dilatarbelakangi perhitungan strategis untuk menjauhkan pengaruh Amerika. Menurut Vrenken (2014:23), perubahan itu juga sudah diusulkan oleh Inggris sejak awal tahun 1944, karena khawatir atas sikap antikolonialisme dari Amerika. Selain itu, Inggris juga merasa kewajiban moral untuk mendukung Belanda yang menjadi sekutunya dalam perang. Bahkan pergantian kepemimpinan dari Konservatif ke Buruh di bawah pimpinan Attlee tidak menggantikan sikap dasar Inggris itu.

Sikap dasar pejabat di tingkat top level Inggris dan Amerika tidak serta merta diterima dan dipatuhi oleh pejabat middle level. Mountbatten sejak semula keberatan dengan limpahan tanggung jawab dari Amerika ke Inggris. Sikap Mountbatten dilatarbelakangi oleh dua alasan. Pertama, Inggris tidak punya cukup niat dan kapasitas untuk menjalankan tugas di Hindia Belanda. Kedua, Mountbatten tidak mempunyai cukup informasi intelijen tentang dinamika di Hindia Belanda, sebagaimana ditulis Winant (1945: 1168): “... Britain did not have readily available sufficient troops and munition or adequate flow of intelligence from Java which would have prepared them for task they would face". Dengan demikian Mountbatten tentu merasa tidak bisa membuat definisi situasi dan karenanya juga tidak mampu membuat respons yang tepat dan memadai. Untuk itu, Mountbatten memberikan sebagian tugas itu kepada pasukan Australia untuk menguasai daerah-daerah kepulauan di luar 
Sumatera dan Jawa. Menurut McMillan (2005:17) Mountbatten justru mendapat informasi yang lebih masuk akal dari istrinya sendiri yang mengadakan perjalanan ke Batavia bahwa situasi dan kondisinya tidak segampang seperti laporan-laporan yang ia terima.

Sikap Pemerintah Belanda terhadap pelimpahan dari Amerika ke Inggris memiliki dinamika tersendiri. Menurut Vrenken (2014:23-25) pada awalnya pemerintah Belanda lebih memilih Inggris daripada Amerika, karena kebijakan anti kolonialisme Amerika. Tetapi ketika transfer terjadi, Belanda menyatakan kurang menyenangi Inggris. Roem (1989:47) menulis bahwa pihak Belanda merasa sangat dirugikan oleh perubahan mendadak, dan Belanda menyindir bahwa Inggris ingin kembali ke Indonesia sebagai pemenang untuk mengembalikan wibawanya, yang hilang sewaktu ia dipukul mundur oleh Jepang. Duta Besar Belanda untuk Amerika, Alexander Loudon, menyatakan bahwa "British did not have the forces, or apparently the will, to do anything about the Indies or to help the Dutch do anything" (Acheson 1945:1163). Ketidaksenangan Belanda itu juga karena Inggris tidak punya niat yang cukup untuk membantu Belanda, dan karena Mountbatten kemudian membagi tugas kepada Australia. Pemerintah Belanda merasa pemerintah Australia tidak mendukung kembalinya kekuasaan Belanda di Hindia Belanda. Namun pada akhirnya, Belanda harus menerima pelimpahan dari Amerika ke Inggris.

Pada tingkat top level, untuk Hindia Belanda, SEAC dibebani tiga tugas utama: (1) melucuti dan merepatriasi tawanan perang orang-orang Jepang, (2) repatriasi POW dan interniran sekutu, dan (3) pemindahan administrasi ke otoritas sipil (McMillan 2005:10, Vrenken 2014:25). Tentu saja, otoritas sipil yang dimaksud dalam kesepakatan Konferensi Postdam adalah pemerintah Hindia Belanda seperti sebelum diambil-alih Jepang. Tetapi di lapangan, masalah-masalah mengenai tiga tugas utama SEAC tersebut banyak bermunculan, seperti: apakah Inggris harus menjaga law and order untuk seluruh wilayah Hindia-Belanda yang amat luas? Sampai kapan proses itu harus berlangsung? Bagaimana menghadapi Republik Indonesia yang sudah de facto? Masalah-masalah tambahan itulah yang menimbulkan perbedaan sikap antar pejabat Inggris.

Mountbatten menyatakan bahwa ia hanya ingin mengendalikan kota-kota pantai di Sumatra dan Jawa (McMillan 2005:4). Secara tegas ia juga menyatakan tidak ingin terlibat dalam politik internal di Hindia Belanda. Kepada van der Plas, Mountbatten menyatakan hanya akan mengamankan wilayahwilayah kunci seperti Batavia dan Surabaya, untuk mengontrol headquarters local Jepang, untuk melaksanakan perlucutan senjata orang-orang Jepang dan memulihkan para tahanan perang (Cumming 1945:1159).

Sikap Mountbatten karena keterbatasan kapasitas militer dan informasi, di samping kurangnya niat dan kepentingan untuk membantu Belanda. Menurut Roem (1989:41-42), karena kekurangan materiil, sedang laporan intel yang dijanjikan oleh Pemerintah Belanda tidak kunjung datang, maka pasukan sekutu yang terdiri dari Pasukan Inggris baru mendarat di Tanjung Priok pada tanggal 29 September, 42 hari sesudah proklamasi.

Sikap Mountbatten itu berbeda dari sikap atasannya, British Chiefs of Staff. Pada 1 Oktober, Chiefs of Staff Inggris mengirim telegram kepada Mountbatten untuk memberitahu kritik dan protes keras dari pemerintah Belanda atas sikap baru Mountbatten, dan untuk meminta Mountbatten melaporkan kebutuhan apa saja yang diperlukan untuk bisa menjalankan tugas menjaga law and order di Hindia Belanda. Tentang hal ini Cumming (1945: 1160) menulis: “... it is clear that the British Chiefs of Staff are giving consideration to modification of Mountbatten's policy in the direction of further assistance to the Dutch." Pada 10-11 Oktober, diadakan pertemuan di Singapura yang dihadiri Mountbatten, Christison, van Mook dan van der Plas Mr untuk mencari kesepakatan antara Inggris dan Belanda tentang bagaimana menghadapi Republik Indonesia. Mountbatten tetap mendesak agar van Mook berunding dengan Soekarno dan Hatta. Mereka akhirnya bersepakat bahwa "Mountbatten would speed up the deployment of British troops to more locations in the interior, while Van Mook agreed to speak to moderate Indonesian nationalists -thereby excluding Sukarno and Hatta" (Vrenken 2014: 35). Dalam hal ini tampak lagi bahwa Mountbatten sedikit merubah sikapnya setelah mengadakan koordinasi dengan para pemimpin lain, baik dari negerinya sendiri maupun dari Belanda. 


\section{Sikap terhadap perlunya Belanda berunding dengan Indonesia}

Kesepakatan tingkat tinggi di Konferensi Postdam akhir Juli 1945 tidak membahas soal bagaimana menghadapi pemerintah dan negara baru, Republik Indonesia, karena memang negara itu belum diproklamasikan. Persoalan berunding atau tidak berunding dengan para pemimpin Indonesia juga tidak dibahas. Tetapi secara implisit, kesepakatan Postdam itu meminta Inggris untuk menjaga Hindia-Belanda sampai Belanda kembali menduduki bekas jajahannya itu. Persoalannya muncul, karena dengan adanya vacum of power yang ditinggalkan Jepang dan belum hadirnya Sekutu ke Indonesia, para pemimpin Indonesia telah memproklamasikan negara baru dan pemerintahnya, maka urusan menjaga law and order secara de facto ada di tangan pemerintah Republik Indonesia. Ketika pasukan Inggris datang, timbul persoalan, untuk menjalankan tugasnya, apakah langsung bertindak sendiri tanpa menghiraukan eksistensi pemerintah Indonesia, atau bekerjasama dengan pemerintah Indonesia.

Secara garis besar, sikap para pejabat Inggris adalah sebagai berikut. Sejak awal Mountbatten menunjukkan sikapnya untuk melakukan kerjasama dengan pemerintah Indonesia. Sikap Mounhtbatten itu diikuti oleh pejabat-pejabat di bawahnya, yaitu Christison dan Mallaby. Tetapi Hawthorn justru mengacaukan sikap Inggris itu, sehingga memicu konflik yang menyebabkan Pertempuran Surabaya. Kendati sejarah tidak mengenal if, namun perlu juga dinyatakan di sini bahwa pertempuran Surabaya mungkin tidak terjadi bila Hawthorn tidak bersikap beda dari Mountbatten, atasannya.

Pada 28 September, Mountbatten mendorong van der Plas sebagai Deputi Gubernur Jendral Hindia Belanda segera berunding di Batavia dengan para pemimpin Indonesia dan mengirim pesan ke van Mook sebagai Pejabat Gubernur Jendral Hindia Belanda dan ke Pemerintah Belanda merekomendasi pengumuman segera untuk "some degree of independence" untuk Indonesia (Cumming 1945:1159).

Brigadir King, pejabat yang dikirim Mountbatten ke Jakarta pada 29 September bersikap seperti Mountbatten, bahkan telah bertindak atas dasar sikap itu. Beberapa hari setelah berada di Indonesia, Panglima Pasukan Inggris di Jakarta memerlukan jasa-jasa dari Kotapraja. Mengenai hal itu, dicatat oleh Roem (1989: 47):

\footnotetext{
"[R]umah-rumah perwira-perwira mereka memerlukan tambahan daya listrik, perbaikan saluran air, pemasangan saluran gas dan telepon, dan pengangkutan sampah. Kecuali itu pasukan Sekutu akan senantiasa memerlukan kerja sama dengan pemerintahan Kota. Oleh karena itu brigadir King langsung menyebut Walikota Suwiryo dengan sebutan "Mr. Mayor", berarti secara otomatis Sekutu telah memberikan pengakuan de facto atas pemerintahan Kota Jakarta Raya."
}

Sikap Mountbatten itu tentu saja ditentang oleh para pejabat Belanda. Van der Plas menyatakan bahwa sikap Mountbatten itu bertentangan dengan harapan Belanda bahwa Inggris akan bertanggungjawab atas law and order untuk seluruh Hindia Belanda sampai datangnya kembali pasukan Belanda. Tetapi tentang berunding dengan para tokoh Indonesia, van der Plas semula setuju dengan Mountbatten bahwa ia "would proceed with the foregoing unless instructed to contrary" (Cumming 1945:1159-1160).

Rekomendasi Mountbatten dan kesediaan van der Plas itu juga ditentang oleh van Mook dan Helfrich. Dari Brisbane van Mook menyatakan bahwa ia tidak bisa memahami posisi Mountbatten karena berbeda dari persetujuan urusan sipil Inggris-Belanda yang mengharuskan Mountbatten bertanggungjawab atas Hindia Belanda. Helfrich menelegram Mountbatten memrotes keinginannya untuk mengadakan konferensi dengan "yang disebut pemerintah Indonesia di bawah Soekarno" (the "so-called Indonesian government of Soekarno") (Cumming 1945:1160).

Mountbatten menjawab protes van Mook dan Helfrich itu dengan menyatakan bahwa Komandan Inggris tidak akan berunding secara personal tetapi sekadar memfasilitasi pengaturan van der Plas untuk bertemu dengan perlbagai pemimpin Indonesia. Sikap ini diambil oleh Mountbatten karena ia 
mengutip keberhasilan perundingan Inggris dengan para pemimpin gerakan kemerdekaan Myanmar sebagai "evidence of the value of such contacts" (Cumming 1945:1160).

Sikap Mountbatten itu disebabkan ia ingin tugas utamanya bisa diselesaikan dengan baik. Tugas itu bisa dilaksanakan kalau tidak ada krisis di internal Hindia Belanda (Moffat 1945b:1171). Tentang perlunya berunding dengan para pemimpin Indonesia, dan kesediaan Belanda berunding asal bukan dengan Soekarno, Mountbatten tegas menyatakan kepada van Mook bahwa "not only would such a meeting without Soekarno be useless but a meeting under those circumstances would prejudice subsequent efforts to smooth the situation" (Moffat 1945a:1166).

Brigjen Mallaby menunjukkan sikap seperti Mountbatten, yaitu memilih berunding dengan para pemimpin Indonesia di Surabaya. Sejak mendarat di Surabaya, Mallaby yakin satu brigade tak akan mampu mengatasi pejuang-pejuang Indonesia di Surabaya. Katanya kepada Kapten Douglas MacDonald: "We come in peace. I want you to bring back the military commander and civilian head of the city with whom I wish to parley" (McMillan 2005:35). Karena itu, selama tiga hari pertamanya di Surabaya (25-27 Oktober 1945), Mallaby lebih mengandalkan dialog dengan Gubernur Suryo dan para pemimpin Indonesia di Surabaya lainnya.

Tetapi Hawthorn, Komandan Divisi India ke-23, punya sikap lain. Ia melarang Mallaby berunding dengan para pemimpin Indonesia. Sebagaimana ditulis McMillan (2005: 38), pada Rabu pagi, 26 Oktober, Hawthorn mengirimkan telgram "Do not parley occupy town" ("Jangan bicara duduki kota") dan siangnya menyebarkan leaflet di kota-kota di Jawa Barat dan Tengah, yang isinya amat provokatif: semua orang Indoensia harus menyerahkan senjata dalam waktu 48 jam. Mallaby menelegram Hawthorn untuk tidak menjatuhkan leaflet itu ke Surabaya, tetapi permintaan itu tak dihiraukan sehingga Kamis pagi, 27 Oktober, tanpa memberitahu Mallaby leaflet-leaflet itu malah dijatuhkan dengan Dakota ke Surabaya.

Mallaby resah dengan sikap dan tindakan Hawthorn. Ia tak habis pikir saat membaca leaflet itu sehingga selama tiga menit ia hanya bisad terdiam. Ketika MacDonald bertanya "What are you going to do, Sir?," Mallaby menjawab galau: "Obey orders" Mallaby amat dilematis. Di satu sisi, ia tahu betul sejak bertolak dari Malaysia ia tidak ditugasi untuk melucuti senjata para pejuang Indonesia. Di sisi lain, Hawthorn adalah atasannya yang harus ditaati (McMillan 2005:40-41).

Tentu saja leaflet itu menyebabkan rakyat Surabaya marah dan tidak lagi mau berunding dengan Mallaby. Rakyat melawan. Perlawanan sengit terjadi pada 28 dan 29 Oktober, dan posisi Brigade ke49 Inggris terkepung di mana-mana. Dalam keadaan sangat terdesak itu, Hawthorn justru meminta Bung Karno, Bung Hatta dan Amir Sjarifuddin untuk ke Surabaya dan menghentikan perang. Tiga pemimpin itu datang ke Surabaya pada 29 Oktober pagi, berhasil mendinginkan suasana. Pada 30 Oktober, para pemimpin Indonesia dan Hawthorn berunding, yang memaksa Hawthorn mau berunding dengan para pimpinan Indonesia dan membatalkan instruksinya sendiri.

Hawthorn bersikap demikian karena ia mengira Surabaya sama dengan Jakarta, yang selama memang serba lebih terkendali dibandingkan di Surabaya, sehingga mengira bahwa satu brigade cukup bisa menaklukan perlawanan arek-arek Suroboyo. Sangat mungkin, keduanya tidak mempunyai informasi intelijen yang memadai tentang situasi dan kondisi di Surabaya. Mereka mengira Surabaya tidak lebih daripada Jakarta. Tentang hal ini Padmodiwiryo (1995: 150) menyatakan bahwa Surabaya lebih kuat daripada Jakarta dan bahkan sering mengejek "rekan-rekan di Jakata [yang] ... hanya berhenti pada pembuatan pamflet dan surat edaran saja".

Mansergh, pengganti Mallaby, punya sikap lain. Kendati masih mau berunding dengan para pemimpin Indonesia di Surabaya, Mansergh menunjukkan sikap bahwa posisi dirinya jauh di atas para pemimpin Indonesia. Padmodiwiryo (1995: 205) menulis: "Sebagai puncak penghinaan, pada akhir surat itu Mansergh memanggil Tuan Suryo supaya datang ke kantornya di Batavia Weg keesokan paginya Jumat tanggal 9 November 1945 pukul 11.00 tepat, untuk menerima perintahperintah lebih lanjut." Gubernur Suryo tidak dianggap sebagai gubernur. Sikap dasarnya itu didasari 
perhitungan bahwa Gubernur Suryo akan mematuhi perintahnya. Kemudian Mansergh mengultimatum pada All Indonesians of Soerabaya untuk menyerahkan diri dengan kata-kata sarkastik di antaranya ditulis oleh Padmodiwiryo (1995: 208) sebagai berikut:

\begin{abstract}
"Mereka harus datang dengan berbaris satu persatu serta membawa segala macam senjata yang ada pada mereka. Segala senjata tersebut diletakkan (ditaruhkan) di tanah pada suatu tempat yang jauhnya seratus meter dari tempat pertemuan itu. Dan kemudian mereka itu harus datang ke muka dengan kedua belah tangannya diangkat ke atas kepalanya masing-masing dan mereka akan ditahan, serta harus menandatangani penyerahan dengan tidak pakai perjanjian apa pun".
\end{abstract}

Penghinaan dan ultimatum atas All Indonesians of Soerabaya itu tidak membuat takut para pemimpin dan rakyat Indoensia di Surabaya, tetapi justru mendorong resistensi lebih kuat dan akhirnya menyebabkan pecahnya Pertempuran Surabaya yang dahsyat itu. Mansergh, seperti halnya Christison dan Hawthorn, tampaknya tidak bisa membuat definisi situasi yang tepat atas kapasitas dan intensitas para pempimpin dan rakyat di Surabaya untuk mempertahankan kemerdekaan, sehingga mengira ultimatumnya akan ditaati.

\title{
Simpulan
}

Secara umum sikap para pejabat Inggris berbeda-beda terhadap dua hal yang diteliti. Ketidakkompakan itu disebabkan oleh perbedaan kepentingan dan kapasitas dalam konteks mereka masing-masing. Data-data yang ditemukan mendukung dua hipotesis dari penelitian ini. Ketika masih di top level, strategi besar (grand strategy) mudah disepakati, artinya sikapnya jelas. Tetapi ketika turun ke strategi dan rencana operasional, perbedaan-perbedaan sikap makin banyak dan sering terjadi. Justru perbedaan-perbedaan itu menjadikan hubungan dinamik, kompleks dan lebih menarik untuk dibahas.

Sikap bahwa pasukan Inggris menjaga law and order di seluruh wilayah bekas Hindia Belanda dipegang oleh para pemimpin di top level di London karena mereka tidak melihat realitas dan tantangan di lapangan yang amat sulit dan rumit. Sikap di top level itu tidak serta merta diterima oleh pejabat di tingkat bawah. Di middle level, Mountbatten semula enggan menerima tanggung jawab, kemudian mengajukan syarat, dan kemudian mengubah sikap itu menjadi menerima tanggung jawab itu secara terbatas, hanya di wilayah-wilayah kota pantai saja. Mountbatten merasa kurang mendapatkan asupan informasi intelijen, tidak mempunyai cukup kekuatan militer, serta kurang melihat kepentingan langsung bagi negaranya.

Sikap Mountbatten di middle level --bahwa para pejabat Inggris dan bahwa Belanda perlu berunding dengan para pemimpin Indonesia-- diikuti secara berbeda oleh bawahan-bawahannya di low level. Christison dan Mallaby menjalankan tugas dengan berunding dengan para pemimpin Indonesia, sementara Hawthorn justru melarang Mallaby melakukan perundingan dengan para pemimpin Indonesia di Surabaya. Sebagai pejabat yang taat azas, walau marah dan hatinya berontak, Mallaby menerima larangan Hawthorn. Sebuah ironi, bahwa pejabat yang setia pada perintah atasannya justru bernasib tragis, sementara atasannya yang melanggar aturan dan sikap atasannya justru selamat.

Larangan Hawthorn itu justru berakibat fatal karena menyulut permusuhan dan mengakibatkan Perang Tiga Hari di akhir Oktober dan Pertempuran Surabaya sejak 10 November 1945. Justru Hawthorn sendiri yang kemudian menganulir larangan kepada Mallaby dan instruksi pamflet yang ia buat sendiri. Kekeliruan Hawthorn itu tampaknya dilatarbelakangi oleh ketidaktepatannya melihat situasi di lapangan, oleh tekanan dari perundingan dengan para pemimpin Indonesia di Surabaya.

Pengganti Mallaby, Mayjen Mansergh, justru makin menekan, menginstruksi dan menggertak para pemimpin Indonesia di Surabaya. Sikap Mansergh itu disebabkan oleh ketidaktepatannya mendefinisikan situasi di Surabaya, atau oleh kepercayaan dirinya karena di-backup oleh mesin perang yang sudah dan sedang dipersiapkan untuk menyerbu Surabaya. 


\section{Daftar Pustaka}

Acheson D (1945) Memorandum of Conversation by Under Secretary of State. 10 October. [Diakses pada 18 Novemver 2016] https://history.state.gov/historicaldocuments/frus1945. 1163-1164.

Cumming HS (1945) Memorandum by the Chief of the Division of Northern European Affairs, Washington, October 8, 1945. [Diakses pada 18 November 2016] https://history.state.gov/historicaldocuments/frus1945. 1158-1163.

David FR (2004) Manajemen Strategis: Konsep-konsep. Jakarta: PT Indeks Kelompok Gramedia.

Kahin AR \& Kahin G Mct (1977) Subversi sebagai Politik Luar Negeri: Menyingkap Keterlibatan CIA di Indonesia. Penerjemah Dr. R.Z. Leirissa. Jakarta: Pustaka Utama Grafiti.

Kroemer KH \& Kromer HJ (1997) Engineering Physiology: Bases of Human Factors/Ergonomics. New York: John Wiley \& Sons.

McMillan R (2005) The British Occupation of Indonesia, 1945-1946: Britain, the Netherlands And the Indonesian Revolution. Royal Asiatic Society Books. New York, NY: Routledge.

Moffat AL (1945a) Memorandum of conversation by the chief of the Division of Southeast Asian Affairs, Washington, October 18, pp. 1165-1167. [Diakses 18 November 2016] https://history.state.gov/historicaldocuments/frus1945.

Moffat AL (1945b) Memorandum of Conversation by the Chief of the Division of Southeast Asian Affairs, Washington, November 8, pp. 1170-1172. [Diakses 18 November 2016] https://history.state.gov/historicaldocuments/frus1945.

Padmodiwiryo S (1995) Memoar Hario Kecik: Autobiografi Seorang Mahasiswa Prajurit. Jakarta: Yayasan Obor Indonesia.

Roem M (1989) Diplomasi: Ujung Tombak Perjuangan RI. Mochtar K (ed). Jakarta: Penerbit PT Gramedia.

Sularto St \& Yunarti DR (2010) Konflik di Balik Proklamasi: BPUPKI, PPKI, Dan Kemerdekaan. Jakarta: Penerbit Buku Kompas.

Susilo IB (2006a) Who Actually Killed Mallaby? The Jakarta Post

Susilo IB (2006b) Who actually killed Mallaby? The Asian Age.

Vrenken M (2014) A common approach? The British and Dutch in the Netherlands East Indies, 19451946. Research Papers No. 5. London: King's College London.

Winant (1945) The Ambassador in the United Kingdom to the Secretary of State. Telegram 7 November, 1168-1169. [Diakses 18 November 2016]. https://history.state.gov/historicaldocuments/frus1945.

Yahaya N (2006) Book Review. Itnerario/Volume 30/Issue 02/July 2006, pp. 220-222. [Diakses 16 Januari 2017]. http://journals.cambridge.org/abstract_S016511530001442X.. 